those with lower income level, French-born in overseas departments, and descendants of non-European immigrants faced a greater risk of occupational exposure to coronavirus before the first lockdown.

Conclusions Our exposure matrix can now be used as an input in ongoing French cohorts to attribute a baseline level of work-related exposure and adjust it based on actual working arrangements during the epidemic. Surveillance of occupational exposure to coronavirus and the socio-demographic characteristics of the workers vulnerable to this virus is key to the implementation of occupation-specific public health response to Covid-19.

\section{P-351 ANALYTICAL PLATFORM FOR EMPLOYEE HEALTH MANAGEMENT}

${ }^{1}$ Evelyn Aaviksoo, Zakariyya Abbasov. ${ }^{1}$ Tervise Teejuht, Estonia

10.1136/OEM-2021-EPI.284

Objective High quality and effective occupational health service (OHS) is heavily dependent on smart use and analysis of data. To provide OHS in an innovative and economically efficient way using real world data and machine learning (ML/AI) we have developed a proof-of-concept (PoC) of an analytical platform HeBA (Health for Business Analytics) to support everyday clinical practice of employee health management.

Methods The innovative approach of HeBA is that it uses naturally collected data of OHS provision and offers analyses based decision support for OHS physicians and for employers. It has modules for physicians (seamlessly integrated with electronic health record system), for individual employees and employer $\mathrm{OH}$ administrators. For managing employees' health in companies HeBA analyses indicators of quality of working life - presentism, stress-level, motivation, sick-leave days and allows to see correlations between working-life quality indicators and health indicators by department, company, economic sector or occupation. Companies can get annually action plans for health management and make an analyses based decisions in employees' and workplace investments. $\mathrm{OH}$ physicians can get rule-based decision support in their everyday practice.

Results HeBA has been tested and used in our OHS clinic serving our clients - 10000 employees. An example of possibilities: we can measure prevalence of poor self-rated health by occupations in datapool of all employees; make comparisons of poor health between departments in a company and assess association of it with workplace risk-factors and health indicators. Qualitative feedback to the PoC from 3 major user groups - physicians, employer administrators and individual employees - has shown very high satisfaction rate and given guidance for further development potential of HeBA.

Conclusion The proof-of-concept has proven its value in improving the OHS quality and efficiency in Estonia. Further research and development is planned for international validation and introducing ML/AI in decision support solutions.

\section{P-353 CHRONIC FATIGUE IN NURSING STAFF WORKING SHIFTS}

${ }^{1}$ Mehrzad Ebrahemzadih, Gholam Hossin Halvani. 'Neyshabur University of Medical Sciences, Islamic Republic of Iran

10.1136/OEM-2021-EPI.285
Introduction The aim of the present study was to determine the association between shift work and chronic fatigue among Educational Hospital nurses.

Methods This cross-sectional study was carried out in an Educational Hospital in Yazd. Using stratified sampling technique, 200 Nurses were selected. The data was collected by using questionnaires about demographics and chronic fatigue. The data was analyzed using SPSS20 software and applying chisquare and Pearson correlation coefficients.

Results 57 male nurses and 143 female nurses participated in this study. There was no significant relation between the gender, marital status, work experience and education level with chronic fatigue. Between age groups with chronic fatigue there was a significant difference. Results from this study showed a significant relation between shift work and chronic fatigue. Chronic fatigue was less frequent among subjects with constant shifts than among those with nonconstant shifts.

Conclusion The relation between shift work and chronic fatigue appears to differ according to constant and non-constant shifts.

\section{P-356 INEQUALITIES IN PESTICIDE POISONING IN BRAZILIAN STATES BY ETHNICITY AND RACE, 2010-2020}

${ }^{1}$ Telma de Cassia dos Santos Nery, Maria Thereza Toledo Penteado, Monize Mendonça Cruz, Tarsila Nery dos Santos Amaral, Paulo Junior Paz De Lilma, Daniel Nery Cardoso, Glaucia Moraes. 'HCFMUSP, Brazil

\subsection{6/OEM-2021-EPI.286}

Brazil is the main consumer of pesticides worldwide. As a consequence, we have observed an increase in cancer cases, high rates of suicides, congenital malformations, high prevalence of mental disorders, high incidence of poisoning in the population in regions with greater use and exposure to pesticides.

Objective To analyze the cases of poisoning notifications by pesticides of use: agricultural, domestic, public health and rodenticides among the Brazilian population, by ethnicity and race.

Methods Descriptive cross-sectional study based on the cases of notifications of pesticide poisoning recorded by DataSUS/ SINAN/MS and SINITOX/Fiocruz, in the Brazilian population, in the period from 2010 to 2020 .

Results Data indicate higher rates of pesticide poisoning in the Black, urban, and young people aged between 20 and 39 years. 116,981 cases of poisoning by pesticides for agricultural use, domestic, public health and rodenticides were reported.

Conclusion Victims of pesticide poisoning do not necessarily need to be economically active, nor do they need to live in the countryside, in a rural area. Poisoning is a problem of the urban Black population, where the largest number of cases are concentrated. Exposures and poisoning by pesticides have been part of the reality of children very early, many are still intoxicated in the wombs of their mothers, rural workers. Therefore, it is a public health problem that needs to be treated with greater attention by governments, health, education and academia professionals, in order to develop specific studies with exposed populations. 